\title{
Antithyroid Drug Treatment in Graves' Disease
}

\section{Jae Hoon Chung}

Division of Endocrinology \& Metabolism, Department of Medicine, Thyroid Center, Samsung Medical Center, Sungkyunkwan University School of Medicine, Seoul, Korea

Graves' disease is associated with thyrotropin (TSH) receptor stimulating antibody, for which there is no therapeutic agent. This disease is currently treated through inhibition of thyroid hormone synthesis or destruction of the thyroid gland. Recurrence after antithyroid drug (ATD) treatment is common. Recent studies have shown that the longer is the duration of use of ATD, the higher is the remission rate. Considering the relationship between clinical outcomes and iodine intake, recurrence of Graves' disease is more common in iodine-deficient areas than in iodine-sufficient areas. Iodine restriction in an iodine-excessive area does not improve the effectiveness of ATD or increase remission rates. Recently, Danish and Korean nationwide studies noted significantly higher prevalence of birth defects in newborns exposed to ATD during the first trimester compared to that of those who did not have such exposure. The prevalence of birth defects was lowest when propylthiouracil (PTU) was used and decreased by only $0.15 \%$ when methimazole was changed to PTU in the first trimester. Therefore, it is best not to use ATD in the first trimester or to change to PTU before pregnancy.

Keywords: Graves disease; Antithyroid agents; Recurrence; Iodine; Congenital abnormalities; Pregnancy

\section{INTRODUCTION}

Graves' disease is the most common cause of hyperthyroidism and is distinguished from thyroiditis, which is caused by release of preformed thyroid hormones into the blood. In Korea, Graves' disease accounts for more than $90 \%$ of hyperthyroidism, followed by thyroiditis. Unlike in Western counties, toxic adenoma and toxic multinodular goiter are extremely rare in Korea. The annual incidence of hyperthyroidism in Korea was 72 cases per 100,000 persons (men 40, women 103), and its prevalence was 340 cases per 100,000 persons (men 209, women 470) [1].

Graves' disease is an autoimmune disease that results from complex interactions between genetic and environmental factors. Thyrotropin (TSH) receptor stimulating antibody (TRAb),

Received: 21 April 2021, Revised: 6 May 2021, Accepted: 10 May 2021

Corresponding author: Jae Hoon Chung

Division of Endocrinology \& Metabolism, Department of Medicine, Thyroid Center, Samsung Medical Center, Sungkyunkwan University School of Medicine, 81 Irwon-ro, Gangnam-gu, Seoul 06351, Korea

Tel: +82-2-3410-3434, Fax: +82-2-3410-3849, E-mail: thyroid@skku.edu which is not present in healthy individuals, continuously stimulates thyroid follicular cells in those with Graves' disease. Ultimately, this leads to excessive production of thyroid hormone and enlargement of the thyroid gland [2]. There is no therapeutic modality targeting TRAb, and the current treatment inhibits thyroid hormone synthesis or destroys the thyroid gland. For this reason, recurrence is common after antithyroid drug (ATD) treatment, the primary therapy for Graves' disease. Sundaresh et al. [3] analyzed recurrence after treatment of 1,402 patients with Graves' disease from eight studies. The recurrence rate after stopping ATD was 53\%, which was significantly higher than that after radioactive iodine (RAI) treatment $(15 \%)$ or surgery $(10 \%)[3]$.

Graves' disease tends to cycle over time, like other autoimmune diseases. Although spontaneous remission is rare in un-

Copyright $\odot 2021$ Korean Endocrine Society

This is an Open Access article distributed under the terms of the Creative Commons Attribution Non-Commercial License (https://creativecommons.org/ licenses/by-nc/4.0/) which permits unrestricted non-commercial use, distribution, and reproduction in any medium, provided the original work is properly cited. 
treated patients, it has been reported [4,5]. Untreated or uncontrolled hyperthyroidism has adverse effects on quality of life and can lead to many complications and death [6-11]. Recently, Kim et al. [12] conducted a nationwide cohort study to compare the incidence and mortality of myocardial infarction and stroke between patients with hyperthyroidism and a control cohort using the Korean National Health Insurance database. They reported that hyperthyroidism significantly increased the risk of myocardial infarction and ischemic stroke, not hemorrhagic stroke, independent of other cardiovascular risk factors, and that it was prominent in patients older than 50 years, women, and non-obese patients. Hyperthyroidism accelerates atherosclerosis by endothelial dysfunction, thyroid autoimmunity, and hypercoagulability [13-15].

\section{OPTIMAL TREATMENT MODALITY OF GRAVES' DISEASE: INITIAL OR AT RECURRENCE}

The initial treatment of Graves' disease involves either ATD or RAI and surgery. There is no optimal treatment, and the choice depends on physician and patient preferences, comorbidities, surgical expertise, medical cost, and social regulation of RAI. In the past, RAI therapy was the most common choice of initial treatment in the United States, while ATD was preferred in Europe and Japan $[16,17]$. However, the preference for treatment modality in the United States has changed recently, with ATD treatment becoming the most common at $58 \%$, followed by RAI treatment at 35\% [18]. In 1992, Cho and Koh [19] translated a global questionnaire on the initial treatment of Graves' disease and asked endocrinologists in Korea. The data showed that 97\% of Korean endocrinologists chose ATD therapy and 3\% chose RAI therapy as the initial treatment for Graves' disease. In 2013, Seo et al. [1] analyzed the medicare claims data using the Korean National Health Insurance database. They reported that $98 \%$ of patients received ATD therapy, $8.2 \%$ received RAI treatment, and $0.9 \%$ received surgery as a treatment modality for Graves' disease. Regarding choice of modality, therapeutic guidelines in most countries recommend that physician and patient collaborate on the decision after discussing the mechanism, strengths and weaknesses, duration, side effects, and costs of each treatment. Abraham-Nordling et al. [7] reported that there was no difference in long-term quality of life of the three treatment modalities.

Twenty years after the first report in 1992, the Korean Thyroid Association (KTA) conducted a similar survey and pub- lished its results in 2013 [20]. Regarding treatment for recurrence, $47 \%$ of respondents chose ATD therapy, $48 \%$ RAI therapy, and the remaining 5\% surgery. In case of recurrence, four factors must be considered that differ from the initial selection [21]. First, many physicians have thought that repeated ATD treatment will result in poor outcomes in case of recurrence. However, a recent Korean study reported a different result [22]. Kim et al. [22] compared the recurrence rates of Graves' patients who were receiving ATD treatment for the first time with those who received it two or more times. They reported that the 10 -year recurrence rate was highest after the third ATD course (71.4\%) compared with that after the first (60.5\%) and second $(58.3 \%)$ courses. Considering that poor compliance is the most common cause of ATD treatment failure, proper drug use must be emphasized at initiation of the second course [23]. If relapsed patients with Graves' disease have ophthalmopathy or refuse an ablative treatment, prolonged low-dose methimazole (MMI) treatment is an alternative [24]. Second, any accompanying disease should be considered before retreatment. In patients with severe comorbidities, such as ischemic heart disease, arrhythmia, and stroke, the accompanying disease can worsen with deterioration of thyroid function during retreatment. Therefore, such patients are encouraged to undergo immediate ablative treatment. Third, if the risk factors of recurrence remain uncorrected, such as huge goiter or high TRAb, ablative treatment should be considered. Fourth, if quality of life has deteriorated or daily activity is reduced for a long time due to frequent deterioration and recurrence, ablative treatment might be preferred, even in young patients.

Several clinical factors, such as male, young age, severe hyperthyroidism, high TRAb before or after treatment, ophthalmopathy, and smoking, have been proposed for predicting poor prognosis after ATD therapy. However, evaluation of these prognostic factors differs by study. This inconsistency might be due to differences in study groups, treatment protocols, definitions of remission or recurrence, or follow-up periods. Therefore, these prognostic factors have a low predictive value and are limited for application in clinical practice. In 2016, Vos et al. [25] conducted a prospective study to design a predictive score, called Graves' Recurrent Events After Therapy (GREAT) score, by combining the four independent risk factors of age, free thyroxine level, TRAb titer, and goiter size for use especially in recurrent Graves' disease. The accuracy of predicted remission with GREAT class I (score 0-1) was 84\%, class II (score 2-3) was $56 \%$, and class III (score 4-6) was $32 \%$. Therefore, ATD treatment was recommended for patients in class I, while RAI 
treatment was recommended for patients in class III. For patients in class II, treatment should be chosen based on additional results of genotyping (human leukocyte antigen [HLA]DQB1-02, DQA1-05, DRB1-03, and protein tyrosine phosphatase, non-receptor type 22 [PTPN22] C/T). In addition, the accuracy of GREAT score might be improved by performing the $\mathrm{TRAb}$ test with a bioassay instead of radioimmunoassay [26, 27].

\section{OPTIMAL DURATION OF ANTITHYROID DRUG TREATMENT}

TRAb plays a pathogenic role in Graves' disease by directly stimulating the thyroid gland. Though Graves' disease can be cured theoretically by removal of TRAb, no such treatment has been developed. Although ATD does not interrupt the development of TRAb or promote its elimination, serum TRAb titer decreases in some patients during ATD treatment. This decrease is independent of the type or dose of ATD and varies in extent $[28,29]$. A previous study suggested that loss of TRAb might not guarantee long-term remission because reemergence can occur when the disease recurs [30]. Considering this observation, remission of Graves' disease after ATD treatment is more likely to be natural rather than due to ATD $[31,32]$.

The long-term remission rate after ATD treatment in patients with Graves' disease is approximately 50\%, ranging from 30 to $70 \%[3,33]$. Recurrence is common within 1 year after stopping ATD [34-37]. Therefore, maintenance of thyroid function at 1 year after stopping ATD is usually defined as remission. The remission rate after ATD treatment differs by region and country, and is mainly associated with duration of its use. In the United States, the remission rate was $20 \%$ to $30 \%$ after ATD treatment for 12 to 18 months, whereas that in Europe was 50\% to $60 \%$ for 5 to 6 years of use [38,39]. Abraham et al. [40] performed a meta-analysis and reported that the remission rate did not increase with ATD used after 18 months. In a Cochrane review of 26 randomized clinical trials with a total of 3,388 patients, the 1 -year recurrence rate after stopping ATD was 51\% and 54\% for block-replace and dose titration, respectively [41]. The review suggested that the optimal duration of ATD treatment was 12 to 18 months. Based on these reports, the recommended duration of ATD treatment proposed by the American Thyroid Association (ATA) is 12 to 18 months. However, Azizi et al. $[42,43]$ performed a meta-analysis and a prospective study that both showed duration of ATD treatment to be positively associated with remission rate. Konishi et al. [44] recommended MMI treatment at a minimum maintenance dose of $2.5 \mathrm{mg} /$ day for at least 6 months after normalization of serum TSH concentration. A recent Korean study demonstrated that the longer that ATD therapy was used, the lower the relapse rate was in patients with Graves' disease, and ATD treatment duration was an independent risk factor for relapse [45]. It showed the relapse rate according to ATD treatment duration was $42.4 \%$ at 1 year, $38.5 \%$ at 2 years, $33.8 \%$ at 3 years, $31.7 \%$ at 4 years, $30.2 \%$ at 5 years, $27.8 \%$ at 6 years, and $19.1 \%$ at more than 6 years, respectively $(P=0.003)$. Bandai et al. [46] reported a plateau in remission rate after ATD treatment for approximately 6.8 years. After 5 years of use, the probability of remission was only $20 \%$ when TRAb was still positive but increased to $89 \%$ when TRAb was disappeared. Considering that the adverse effects of ATD are proportional to the administered dose, there is little concern about adverse effects from long-term, low-dose maintenance therapy. The reported frequency of severe adverse effects in such conditions was $1.5 \%$ [42].

The ATA suggests that MMI treatment is stopped when serum TSH level is normalized, and that the TRAb titer is measured before stopping ATD. If TRAb is not detectable, the likelihood of remission increases [47]. The ATA recommends that ATD is stopped when serum TSH level is normalized even if the TRAb titer is high. However, due to the high recurrence rate under this condition, more frequent thyroid function tests are recommended. Contrary to the ATA recommendations, most Korean endocrinologists considered it more important that TRAb became negative before stopping ATD, resulting in an ATD treatment period longer than 18 months. Based on the treatment principles for hyperthyroidism suggested by the KTA, most Korean endocrinologists continue ATD treatment until achieving a target of normalized serum TSH and negative TRAb [20].

\section{OPTIMAL FOLLOW-UP DURATION AFTER STOPPING ANTITHYROID DRUG}

A Swedish study demonstrated that half of the relapses occurred within 6 months and two-thirds occurred within 1 year after stopping ATD [33]. It suggested excellent long-term prognosis without recurrence after 4 years. A more recent Korean study noted that $50 \%$ of the recurrences developed within 1 year after stopping ATD, and more than $90 \%$ of the recurrences were observed within 4 years [22]. Considering these results, it is advisable to follow patients for at least 1 and up to 4 years after stopping ATD. 


\section{IODINE INTAKE DURING TREATMENT OF GRAVES' DISEASE}

The relationship between iodine intake and effects of ATD on Graves' disease has been demonstrated in many studies since the 1980s. In 1985, an epidemiological study in Iran reported that patients with Graves' disease in an iodine-sufficient area showed resistance to ATD and more frequent recurrence [48]. In 1987, Solomon et al. [49] reported that the remission rate was associated with decreased iodine intake, and high iodine intake adversely influenced the effectiveness of ATD. In 1993, Roti et al. [50] reported that some euthyroid patients with a history of ATD treatment for Graves' disease develop thyroid dysfunction during and after excessive iodine intake. However, in recent years, different results from previous studies have been published. In 2011, Pramyothin et al. [51] reported that recurrence of Graves' disease occurred more frequently in iodine-deficient areas than in iodine-sufficient areas. A high relapse rate up to 67.5\% after stopping ATD has been reported in Copenhagen, Denmark, in which the iodine intake is relatively low compared to other countries [52].

Although a previous study has shown significantly increased titer of thyroid autoantibodies after iodine supply in an iodinedeficient area, recent experimental studies showed the opposite results [53-55]. Two experimental studies have revealed that iodine in the thyroid gland regulates the expression of thyroidspecific proteins via negative feedback, indicating that restricted iodine intake would increase the expression of these specific proteins, enhance thyroid hormone synthesis, and lead to a more severe autoimmune response $[54,55]$.

A recent prospective study in China compared treatment outcomes of ATD in Graves' patients with iodine supplementation (urinary iodine concentration [UIC], 135 to $162 \mu \mathrm{g} / \mathrm{L}$ ) with those of patients with iodine restriction (UIC 30 to $58 \mu \mathrm{g} / \mathrm{L}$ ) [56]. The recurrence rate within 12 months after stopping ATD was significantly lower in the iodine supplementation group than in the iodine-restricted group (35.5\% vs. $45.5 \%)$. Interestingly, the median titer of TRAb in the iodine-supplementation group gradually decreased from $26.8 \mathrm{mU} / \mathrm{L}$ at the beginning of treatment to $1.6 \mathrm{mU} / \mathrm{L}$ at 24 months, whereas that in the iodinerestricted group decreased from 25.9 to $6.5 \mathrm{mU} / \mathrm{L}$, but the degree showed a significant difference $(P<0.001)$. They suggested that optimal dietary iodine supplementation during ATD therapy for Graves' disease was associated with lower recurrence rates than iodine restriction. Recently, the relationship between iodine intake and clinical outcomes of Graves' disease in an iodine-ex- cessive area has been demonstrated. In 2006, a prospective randomized controlled study in Japan reported that iodine restriction does not ameliorate the effect of ATD therapy on Graves' disease in an iodine-excessive area [57]. They attributed this result to unique dietary habit in the Japanese population and postulated that the thyroid gland probably has a large reservoir of preformed thyroid hormones. Subsequently, in 2015, a Korean study demonstrated that excessive iodine intake does not increase the recurrence rate of Graves' disease after stopping ATD [58]. Remission rate in the excessive iodine intake group (UIC $\geq 300 \mu \mathrm{g} / \mathrm{L}$ ) did not differ from that of the average iodine intake group (UIC $<300 \mu \mathrm{g} / \mathrm{L}$ ). This suggested that iodine restriction might not be necessary during ATD treatment for Graves' disease in iodine-excessive areas. The amount of iodine intake might not alter the intrinsic regulatory mechanism of thyroid hormone synthesis, especially in the environment of chronic exposure to sufficient dietary iodine [58].

In conclusion, recurrence of Graves' disease is more common in iodine-deficient areas. Therefore, sufficient iodine supply is needed to lower the recurrence rate in iodine-deficient areas. In addition, iodine restriction does not improve the effectiveness of ATD or increase remission rate, and iodine restriction might not be necessary during ATD treatment in iodine-excessive areas.

\section{ANTITHYROID DRUGS DURING PREGNANCY AND BIRTH DEFECTS}

ATD is a mainstay for treatment of hyperthyroidism during pregnancy. The therapeutic effects of propylthiouracil (PTU), MMI, and carbimazole (CMZ) are the same as a treatment modality for hyperthyroidism during pregnancy [59]. Since all ATDs pass through the placenta during pregnancy, they can cause problems with organogenesis, especially in the first trimester [60]. In 2009, concern of a rare but fatal PTU-induced hepatotoxicity was raised $[61,62]$. The U.S. Food and Drug Administration (FDA) and the ATA recommended PTU use only in the first trimester, switching to MMI by the second trimester $[63,64]$. However, this recommendation had potential problems that overlooked other adverse effects from both drugs.

In 2013, a Danish nationwide study reported that all ATDs used during early pregnancy were significantly associated with birth defects (PTU 8.0\%, MMI/CMZ 9.1\%, both $10.1 \%$, no ATD 5.4\%, non-exposed 5.7\%) [65]. In 2019, the group repeated their study with a larger number of subjects and reported similar results (PTU 8.3\%, MMI/CMZ 9.6\%, non-exposed $6.7 \%$ ) [66]. They also reported that abnormal maternal thyroid 
function was not a major risk factor for birth defects.

Recently, a Korean nationwide study using the Korean National Health Insurance database was conducted to examine the association between ATD used during the first trimester and birth defects in 2,885,000 pregnant women [67]. The study reported that the prevalence of birth defects in newborns exposed to ATDs during the first trimester was significantly higher than that of those who did not (PTU 7.04\%, MMI 8.13\%, both $7.98 \%$, no ATD 5.94\%). The use of PTU during the first trimester lowered the prevalence of birth defects by $1.1 \%$ compared to the use of MMI, but even if the MMI was changed to PTU during the first trimester, the prevalence of birth defects was only reduced by $0.15 \%$ compared to the case of continued use of MMI (Table 1). This study also suggested that PTU was associ- ated with musculoskeletal and urogenital defects, while MMI was associated with defects of nervous, circulatory, and digestive systems and MMI embryopathy. Birth defects occurred from the onset of PTU use, and there was no difference in prevalence of birth defects by dose or duration of PTU. On the other hand, birth defects caused by MMI occurred at a low frequency with use of a small dose but increased abruptly with duration of use of 1.5 months or more or at a dose of $495 \mathrm{mg}$ or greater (Fig. 1). They concluded that it is best not to use ATDs in the first trimester, followed by changing to PTU before pregnancy. If $\mathrm{MMI}$ is unavoidable in the first trimester, it is recommended to use a cumulative dose less than $495 \mathrm{mg}$ for fewer than 1.5 months.

Table 1. Absolute Risk Differences and Odds Ratios for Overall Birth Defects in Pregnancies in Which Women Were Prescribed AntiThyroid Drugs during the First Trimester

\begin{tabular}{|c|c|c|c|c|c|}
\hline Antithyroid drugs & Pregnancy & Birth defects, $n(\%)$ & Risk differences $^{\mathrm{a}}(95 \% \mathrm{CI})$ & Odds ratio $^{\mathrm{b}}(95 \% \mathrm{CI})$ & $P$ value \\
\hline Continued MMI alone & 909 & $70(7.70)$ & 0 (reference) & 1.00 (reference) & \\
\hline MMI to PTU & 2,079 & $166(7.98)$ & $3.97(-16.82$ to 24.76$)$ & $1.06(9.79$ to 1.42$)$ & NS \\
\hline Both MMI \& PTU & 250 & $19(7.60)$ & 0.82 ( -36.63 to 38.28$)$ & $1.01(0.60$ to 1.72$)$ & NS \\
\hline Continued PTU alone & 5,184 & $357(6.89)$ & 0 (reference) & 1.00 (reference) & \\
\hline PTU to MMI & 158 & $18(11.39)$ & $47.26(-3.04$ to 97.57$)$ & 1.79 (1.08 to 2.97$)$ & 0.024 \\
\hline Both MMI \& PTU & 250 & $19(7.60)$ & $9.32(-24.91$ to 43.55$)$ & $1.15(0.71$ to 1.86$)$ & NS \\
\hline
\end{tabular}

Adapted from Seo et al. [67], with permission from The American College of Physicians.

CI, confidence interval; MMI, methimazole; PTU, propylthiouracil; NS, not significant.

${ }^{a}$ Risk difference per 1,000 live births, standardized by maternal age, birth year, multiple pregnancies, and infant sex; ${ }^{\mathrm{b}}$ Adjusted for maternal age, birth years, multiple pregnancies, and infant sex.

Propylthiouracil

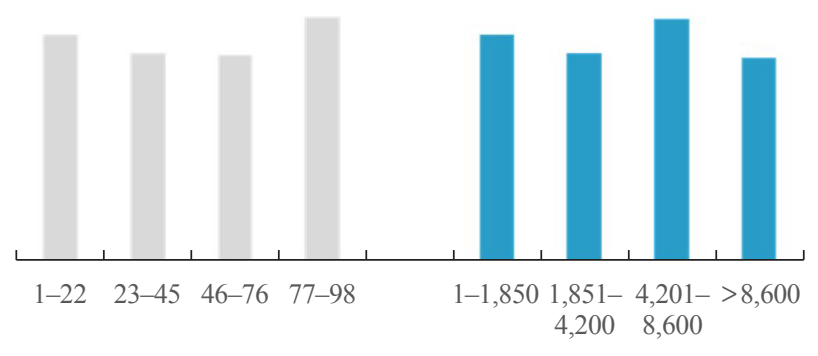

Duration (day)

Cumulative dose (mg)

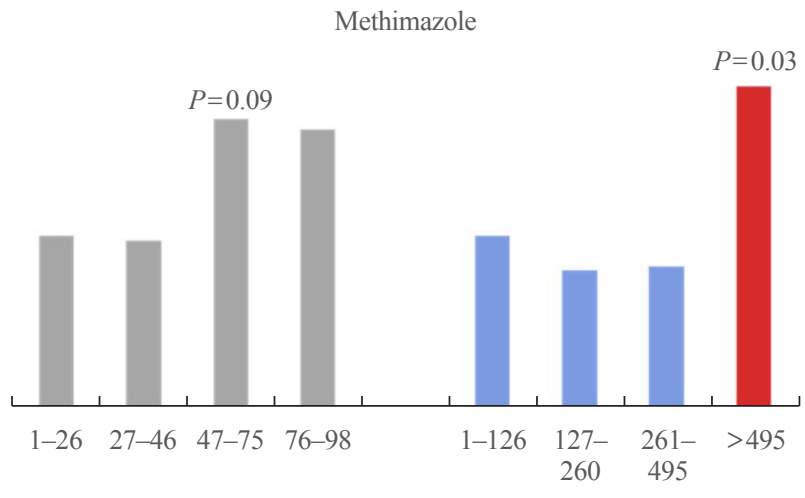

Duration (day)

Cumulative dose (mg)

Fig. 1. The prevalence of birth defects in pregnancies exposed to antithyroid drugs during the first trimester by drug type, duration, and cumulative dose. Birth defects occurred from the onset of propylthiouracil (PTU) use during the first trimester, and the risk for birth defects did not differ with the duration and cumulative dose of PTU. However, a high cumulative dose of methimazole ( $>495 \mathrm{mg})$ during the first trimester was associated with an increased risk for birth defects compared with a low dose (1 to $126 \mathrm{mg}$ ) (adjusted odds ratio, 1.87 ; $95 \%$ confidence interval, 1.06 to 3.30). Adapted from Seo et al. [67], with permission from The American College of Physicians. 


\section{CONCLUSIONS}

Recurrence after ATD treatment for Graves' disease is common. Recent studies have demonstrated that the longer is the duration of use of ATD, the higher is the remission rate. Recurrence of Graves' disease is more common in iodine-deficient areas than in iodine-sufficient areas. Iodine restriction in an iodine-excessive area is not necessary to improve the effectiveness of ATD or increase remission rates. Recent two nationwide studies showed higher prevalence of birth defects in newborns exposed to ATD during the first trimester compared to that of those who did not have such exposure. It is best not to use ATD in the first trimester or to change to PTU before pregnancy.

\section{CONFLICTS OF INTEREST}

No potential conflict of interest relevant to this article was reported.

\section{ORCID}

Jae Hoon Chung https://orcid.org/0000-0002-9563-5046

\section{REFERENCES}

1. Seo GH, Kim SW, Chung JH. Incidence \& prevalence of hyperthyroidism and preference for therapeutic modalities in Korea. J Korean Thyroid Assoc 2013;6:56-63.

2. Smith TJ, Hegedus L. Graves' disease. N Engl J Med 2016; 375:1552-65.

3. Sundaresh V, Brito JP, Wang Z, Prokop LJ, Stan MN, Murad $\mathrm{MH}$, et al. Comparative effectiveness of therapies for Graves' hyperthyroidism: a systematic review and network meta-analysis. J Clin Endocrinol Metab 2013;98:3671-7.

4. Codaccioni JL, Orgiazzi J, Blanc P, Pugeat M, Roulier R, Carayon P. Lasting remissions in patients treated for Graves' hyperthyroidism with propranolol alone: a pattern of spontaneous evolution of the disease. J Clin Endocrinol Metab 1988;67:656-62.

5. Nagai Y, Toya T, Fukuoka K, Tanaka N, Yanagi S, Kobayashi K. Occurrence and spontaneous remission of Graves' hyperthyroidism preceded by painless thyroiditis. Endocr J 1997;44:881-5.

6. Klein I, Ojamaa K. Thyroid hormone and the cardiovascular system. N Engl J Med 2001;344:501-9.

7. Abraham-Nordling M, Torring O, Hamberger B, Lundell G,
Tallstedt L, Calissendorff J, et al. Graves' disease: a longterm quality-of-life follow up of patients randomized to treatment with antithyroid drugs, radioiodine, or surgery. Thyroid 2005;15:1279-86.

8. Brandt F, Thvilum M, Almind D, Christensen K, Green A, Hegedus L, et al. Graves' disease and toxic nodular goiter are both associated with increased mortality but differ with respect to the cause of death: a Danish population-based register study. Thyroid 2013;23:408-13.

9. Cramon P, Winther KH, Watt T, Bonnema SJ, Bjorner JB, Ekholm O, et al. Quality-of-life impairments persist six months after treatment of Graves' hyperthyroidism and toxic nodular goiter: a prospective cohort study. Thyroid 2016;26: 1010-8.

10. Giesecke P, Rosenqvist M, Frykman V, Friberg L, Wallin G, Hoijer J, et al. Increased cardiovascular mortality and morbidity in patients treated for toxic nodular goiter compared to Graves' disease and nontoxic goiter. Thyroid 2017;27: 878-85.

11. Sohn SY, Lee E, Lee MK, Lee JH. The association of overt and subclinical hyperthyroidism with the risk of cardiovascular events and cardiovascular mortality: meta-analysis and systematic review of cohort studies. Endocrinol Metab (Seoul) 2020;35:786-800.

12. Kim HJ, Kang T, Kang MJ, Ahn HS, Sohn SY. Incidence and mortality of myocardial infarction and stroke in patients with hyperthyroidism: a nationwide cohort study in Korea. Thyroid 2020;30:955-65.

13. Burggraaf J, Lalezari S, Emeis JJ, Vischer UM, de Meyer $\mathrm{PH}, \mathrm{Pij} 1 \mathrm{H}$, et al. Endothelial function in patients with hyperthyroidism before and after treatment with propranolol and thiamazol. Thyroid 2001;11:153-60.

14. Matsuura E, Atzeni F, Sarzi-Puttini P, Turiel M, Lopez LR, Nurmohamed MT. Is atherosclerosis an autoimmune disease? BMC Med 2014;12:47.

15. Bano A, Chaker L, de Maat MPM, Atiq F, Kavousi M, Franco $\mathrm{OH}$, et al. Thyroid function and cardiovascular disease: the mediating role of coagulation factors. J Clin Endocrinol Metab 2019;104:3203-12.

16. Wartofsky L, Glinoer D, Solomon B, Nagataki S, Lagasse R, Nagayama Y, et al. Differences and similarities in the diagnosis and treatment of Graves' disease in Europe, Japan, and the United States. Thyroid 1991;1:129-35.

17. Burch HB, Burman KD, Cooper DS. A 2011 survey of clinical practice patterns in the management of Graves' disease. J Clin Endocrinol Metab 2012;97:4549-58. 
18. Brito JP, Schilz S, Singh Ospina N, Rodriguez-Gutierrez R, Maraka S, Sangaralingham LR, et al. Antithyroid drugs: the most common treatment for Graves' disease in the United States. A nationwide population-based study. Thyroid 2016; 26:1144-5.

19. Cho BY, Koh CS. Current trends in the diagnosis and treatment of Graves' disease in Korea. J Korean Soc Endocrinol 1992;7:216-27.

20. Yi KH, Moon JH, Kim IJ, Bom HS, Lee J, Chung WY, et al. The diagnosis and management of hyperthyroidism consensus: report of the Korean Thyroid Association. J Korean Thyroid Assoc 2013;6:1-11.

21. Chung JH. Treatment of relapsed hyperthyroidism. J Korean Med Assoc 2018;61:248-52.

22. Kim YA, Cho SW, Choi HS, Moon S, Moon JH, Kim KW, et al. The second antithyroid drug treatment is effective in relapsed Graves' disease patients: a median 11-year followup study. Thyroid 2017;27:491-6.

23. Cooper DS. Propylthiouracil levels in hyperthyroid patients unresponsive to large doses. Evidence of poor patient compliance. Ann Intern Med 1985;102:328-31.

24. Villagelin D, Romaldini JH, Santos RB, Milkos AB, Ward LS. Outcomes in relapsed Graves' disease patients following radioiodine or prolonged low dose of methimazole treatment. Thyroid 2015;25:1282-90.

25. Vos XG, Endert E, Zwinderman AH, Tijssen JG, Wiersinga WM. Predicting the risk of recurrence before the start of antithyroid drug therapy in patients with Graves' hyperthyroidism. J Clin Endocrinol Metab 2016;101:1381-9.

26. Giuliani C, Cerrone D, Harii N, Thornton M, Kohn LD, Dagia NM, et al. A TSHR-LH/CGR chimera that measures functional thyroid-stimulating autoantibodies (TSAb) can predict remission or recurrence in Graves' patients undergoing antithyroid drug (ATD) treatment. J Clin Endocrinol Metab 2012;97:E1080-7.

27. Kwon H, Kim WG, Jang EK, Kim M, Park S, Jeon MJ, et al. Usefulness of measuring thyroid stimulating antibody at the time of antithyroid drug withdrawal for predicting relapse of Graves disease. Endocrinol Metab (Seoul) 2016;31: 300-10.

28. Weetman AP, McGregor AM, Hall R. Evidence for an effect of antithyroid drugs on the natural history of Graves' disease. Clin Endocrinol (Oxf) 1984;21:163-72.

29. Davies TF. Autoimmune thyroid disease genes come in many styles and colors. J Clin Endocrinol Metab 1998;83: 3391-3.
30. Feldt-Rasmussen U, Schleusener H, Carayon P. Meta-analysis evaluation of the impact of thyrotropin receptor antibodies on long term remission after medical therapy of Graves' disease. J Clin Endocrinol Metab 1994;78:98-102.

31. Laurberg P, Wallin G, Tallstedt L, Abraham-Nordling M, Lundell G, Torring O. TSH-receptor autoimmunity in Graves' disease after therapy with anti-thyroid drugs, surgery, or radioiodine: a 5-year prospective randomized study. Eur J Endocrinol 2008;158:69-75.

32. Laurberg P, Krejbjerg A, Andersen SL. Relapse following antithyroid drug therapy for Graves' hyperthyroidism. Curr Opin Endocrinol Diabetes Obes 2014;21:415-21.

33. Mohlin E, Filipsson Nystrom H, Eliasson M. Long-term prognosis after medical treatment of Graves' disease in a northern Swedish population 2000-2010. Eur J Endocrinol 2014;170:419-27.

34. Tamai H, Nakagawa T, Fukino O, Ohsako N, Shinzato R, Suematsu H, et al. Thionamide therapy in Graves' disease: relation of relapse rate to duration of therapy. Ann Intern Med 1980;92:488-90.

35. Schleusener H, Schwander J, Fischer C, Holle R, Holl G, Badenhoop K, et al. Prospective multicentre study on the prediction of relapse after antithyroid drug treatment in patients with Graves' disease. Acta Endocrinol (Copenh) 1989; 120:689-701.

36. Hedley AJ, Young RE, Jones SJ, Alexander WD, Bewsher PD. Antithyroid drugs in the treatment of hyperthyroidism of Graves' disease: long-term follow-up of 434 patients. Scottish Automated Follow-Up Register Group. Clin Endocrinol (Oxf) 1989;31:209-18.

37. Garcia-Mayor RV, Paramo C, Luna Cano R, Perez Mendez LF, Galofre JC, Andrade A. Antithyroid drug and Graves' hyperthyroidism. Significance of treatment duration and $\mathrm{TRAb}$ determination on lasting remission. J Endocrinol Invest 1992;15:815-20.

38. Klein I, Becker DV, Levey GS. Treatment of hyperthyroid disease. Ann Intern Med 1994;121:281-8.

39. Mazza E, Carlini M, Flecchia D, Blatto A, Zuccarini O, Gamba S, et al. Long-term follow-up of patients with hyperthyroidism due to Graves' disease treated with methimazole. Comparison of usual treatment schedule with drug discontinuation vs continuous treatment with low methimazole doses: a retrospective study. J Endocrinol Invest 2008;31: 866-72.

40. Abraham P, Avenell A, Park CM, Watson WA, Bevan JS. A systematic review of drug therapy for Graves' hyperthyroid- 
ism. Eur J Endocrinol 2005;153:489-98.

41. Abraham P, Avenell A, McGeoch SC, Clark LF, Bevan JS. Antithyroid drug regimen for treating Graves' hyperthyroidism. Cochrane Database Syst Rev 2010;2010:CD003420.

42. Azizi F, Malboosbaf R. Long-term antithyroid drug treatment: a systematic review and meta-analysis. Thyroid 2017; 27:1223-31.

43. Azizi F, Amouzegar A, Tohidi M, Hedayati M, Khalili D, Cheraghi $\mathrm{L}$, et al. Increased remission rates after long-term methimazole therapy in patients with Graves' disease: results of a randomized clinical trial. Thyroid 2019;29:1192200.

44. Konishi T, Okamoto Y, Ueda M, Fukuda Y, Harusato I, Tsukamoto Y, et al. Drug discontinuation after treatment with minimum maintenance dose of an antithyroid drug in Graves' disease: a retrospective study on effects of treatment duration with minimum maintenance dose on lasting remission. Endocr J 2011;58:95-100.

45. Park SY, Kim BH, Kim M, Hong AR, Park J, Park H, et al. The longer the antithyroid drug is used, the lower the relapse rate in Graves' disease: a retrospective multicenter cohort study in Korea. Endocrine 2021 Apr 15 [Epub]. https://doi. org/10.1007/s12020-021-02725-x.

46. Bandai S, Okamura K, Fujikawa M, Sato K, Ikenoue H, Kitazono T. The long-term follow-up of patients with thionamide-treated Graves' hyperthyroidism. Endocr J 2019;66: 535-45.

47. Ross DS, Burch HB, Cooper DS, Greenlee MC, Laurberg P, Maia AL, et al. 2016 American Thyroid Association guidelines for diagnosis and management of hyperthyroidism and other causes of thyrotoxicosis. Thyroid 2016;26:1343-421.

48. Azizi F. Environmental iodine intake affects the response to methimazole in patients with diffuse toxic goiter. J Clin Endocrinol Metab 1985;61:374-7.

49. Solomon BL, Evaul JE, Burman KD, Wartofsky L. Remission rates with antithyroid drug therapy: continuing influence of iodine intake? Ann Intern Med 1987;107:510-2.

50. Roti E, Gardini E, Minelli R, Bianconi L, Salvi M, Gavaruzzi G, et al. Effects of chronic iodine administration on thyroid status in euthyroid subjects previously treated with antithyroid drugs for Graves' hyperthyroidism. J Clin Endocrinol Metab 1993;76:928-32.

51. Pramyothin P, Leung AM, Pearce EN, Malabanan AO, Braverman LE. Clinical problem-solving. A hidden solution. N Engl J Med 2011;365:2123-7.

52. Lumholtz IB, Poulsen DL, Siersbaek-Nielsen K, Friis T,
Rogowski P, Kirkegaard C, et al. Outcome of long-term antithyroid treatment of Graves' disease in relation to iodine intake. Acta Endocrinol (Copenh) 1977;84:538-41.

53. Pedersen IB, Knudsen N, Carle A, Vejbjerg P, Jorgensen T, Perrild $\mathrm{H}$, et al. A cautious iodization programme bringing iodine intake to a low recommended level is associated with an increase in the prevalence of thyroid autoantibodies in the population. Clin Endocrinol (Oxf) 2011;75:120-6.

54. Huang H, Shi Y, Lin L, Li L, Lin X, Li X, et al. Inhibition of thyroid-restricted genes by follicular thyroglobulin involves iodinated degree. J Cell Biochem 2011;112:971-7.

55. Huang H, Chen L, Liang B, Cai H, Cai Q, Shi Y. Upregulation of TSHR, TTF-1, and PAX8 in nodular goiter is associated with iodine deficiency in the follicular lumen. Int J Endocrinol 2016;2016:2492450.

56. Huang H, Shi Y, Liang B, Cai H, Cai Q, Lin R. Optimal iodine supplementation during antithyroid drug therapy for Graves' disease is associated with lower recurrence rates than iodine restriction. Clin Endocrinol (Oxf) 2018;88:4738 .

57. Hiraiwa T, Ito M, Imagawa A, Takamatsu J, Kuma K, Miyauchi A, et al. Restriction of dietary iodine does not ameliorate the early effect of anti-thyroid drug therapy for Graves' disease in an area of excessive iodine intake. J Endocrinol Invest 2006;29:380-4.

58. Park SM, Cho YY, Joung JY, Sohn SY, Kim SW, Chung JH. Excessive iodine intake does not increase the recurrence rate of Graves' disease after withdrawal of the antithyroid drug in an iodine-replete area. Eur Thyroid J 2015;4:36-42.

59. Wing DA, Millar LK, Koonings PP, Montoro MN, Mestman $\mathrm{JH}$. A comparison of propylthiouracil versus methimazole in the treatment of hyperthyroidism in pregnancy. Am J Obstet Gynecol 1994;170(1 Pt 1):90-5.

60. Mortimer RH, Cannell GR, Addison RS, Johnson LP, Roberts MS, Bernus I. Methimazole and propylthiouracil equally cross the perfused human term placental lobule. J Clin Endocrinol Metab 1997;82:3099-102.

61. Rivkees SA, Mattison DR. Ending propylthiouracil-induced liver failure in children. N Engl J Med 2009;360:1574-5.

62. Bahn RS, Burch HS, Cooper DS, Garber JR, Greenlee CM, Klein IL, et al. The role of propylthiouracil in the management of Graves' disease in adults: report of a meeting jointly sponsored by the American Thyroid Association and the Food and Drug Administration. Thyroid 2009;19:673-4.

63. Bahn Chair RS, Burch HB, Cooper DS, Garber JR, Greenlee MC, Klein I, et al. Hyperthyroidism and other causes of 
thyrotoxicosis: management guidelines of the American Thyroid Association and American Association of Clinical Endocrinologists. Thyroid 2011;21:593-646.

64. Alexander EK, Pearce EN, Brent GA, Brown RS, Chen H, Dosiou C, et al. 2017 Guidelines of the American Thyroid Association for the diagnosis and management of thyroid disease during pregnancy and the postpartum. Thyroid 2017; 27:315-89.

65. Andersen SL, Olsen J, Wu CS, Laurberg P. Birth defects af- ter early pregnancy use of antithyroid drugs: a Danish nationwide study. J Clin Endocrinol Metab 2013;98:4373-81.

66. Andersen SL, Knosgaard L, Olsen J, Vestergaard P, Andersen S. Maternal thyroid function, use of antithyroid drugs in early pregnancy, and birth defects. J Clin Endocrinol Metab 2019;104:6040-8.

67. Seo GH, Kim TH, Chung JH. Antithyroid drugs and congenital malformations: a nationwide Korean cohort study. Ann Intern Med 2018;168:405-13. 